\title{
DIOGO DE TEIVE E PEDRO DE VELASCO SUPOSTOS DESCOBRIDORES DO BANCO DA TERRA NOVA.
}

O historiador Jaime Cortesão, fértil em fantasiar descobertas marítimas pré-colombianas e atribuílas a nautas portuguêses, publicou no Arquivo Histórico da Marinha (1) um trabalho aparentemente bem arquitetado, visando emprestar a Diogo de Teive, madeirense, escudeiro do Infante D. Henrique e ao seu pilôto Pedro de Velasco, "a glória" de terem em agôsto de 1452 avistado o banco da Terra Nova, sem todavia tê-lo abordado.

Essa tese de Jaime Cortesão tendo sido refutada com evidente vantagem pelo notável historiador norte-americano Samuel Eliot Morison (2), pelo erudito e probo professor Duarte Leite (3) e também por nós (4), devia ser considerada assunto superado por ser fruto de desmedida vaidade nacional. Tal porém não ocorre, pois ao ser comemorado agora o V centenário da morte do Infante $\mathrm{D}$. Henrique, com grande surprêsa nossa, o emérito professor Damião Peres (5) passa a defendêla com calor e com esta hipérbole: O Infante D. Henrique não acreditava que o então Mar Oceano banhasse de um lado o Extremo Oriente asiático e de outro o Extremo Ocidente euroafricano, conforme a geografia ptolomaica. Admitia êsse príncipe a existência de ilhas e até de um continente interposto entre as costas orientais da Asia e as ocidentais da Europa e Africa, como é em realidade. Como se vê, concepção genial que só por divina revelação podia $\mathrm{D}$. Henrique arquitetar, dado o seu minguado saber em astronomia e geografia, o que é atestado pelos seus honestos biógrafos. Como prova de ter êste príncipe mandado perlustrar o Atlântico ocidental para

(1). - Arquivo Histórico da Marinha, Lisboa, 1933, volume 1.

(2). - Portuguese Voyages to America in the Fifteenth Century, Cambridge, 1940, páginas 21 a 29.

(3). - Coisas de Vária História, Lisboa, 1941, páginas 68 a 81 .

(4). - o Descobrimento do Brasil, São Paulo, 1946. páginas 11 a 23.

(5). - o seculo dos Descobrimentos, Suplemento Literário do jornal o Estado de s. Paulo, 12 de novembro de 1960, página 1. 
certificar-se do acerto de sua piramidal idéia, cita o emérito professor Damião Peres a viagem do aludido madeirense às regiões setentrionais da América.

Não era nossa intenção ventilar de novo tal assunto, mas como o ilustre professor cita o nosso nome e procura contestar um dos tópicos do que escrevemos sôbre a viagem de Diogo de Teive, voltamos a debater a questão com o escopo de provar o acerto da nossa opinião que é diametralmente oposta àquela de Cortesão e, conseqüentemente à sua .

Os textos fundamentais que, na opinião de Cortesão, fazem referência à suposta viagem de tal navegante à referida região setentrional da Amércia em 1452, são os seguintes: o capítulo IX da Historie della vita e dei fatti di Cristoforo Colombo, pelo seu filho D. Fernando Colombo, e o capítulo XIII da Historia de las Indias por Bartolomeu de Las Casas. Aquela editada em Veneza em 1571 e esta escrita entre 1552 a 1561, mas só publicada em Madrí em 1875.

Além dessas fontes, recorreu Cortesão aos depoimentos de duas testemunhas de nome Alonso Velez Allid e Fernando Valiente, que depuseram em las probanzas dos chamados Pleitos de Colón, referentes ao período de 1532 a 1535, com o escopo de deixar bem evidenciado ter sido Colombo informado em Santa Maria de la Rabida, da viagem de Teive e seu pilôto ao suposto banco da Terra Nova. Para isso, o referido historiador português procurou identificar Pedro Vasquez de la Fronteira a que alude essas testemunhas dos Pleitos de Colón, com Pedro de Velasco dos textos de D. Fernando e de Las Casas.

Vamos transcrever aqui o que sôbre a viagem de Diogo de Teive e mais o seu pilôto Pedro de Velasco escreveu D. Fernando Colombo e bem assim os tópicos dos depoimentos das citadas testemunhas dos Pleitos de Colón que interessam à presente discussão.

Diz D. Fernando Colombo o seguinte:

"Andò ancora a cercar quest'Isola un certo Diego da Tiene, il cui piloto, chiamato Pietro di Velasco, nativo di Palos di Mogher, disse all "Amiraglio in Santa Maria della Rabida: ch'essi partirono dal Fagial, e navigarono più di cento e cinquenta leghe per Libecchio, e nel tornare indietro scoprirono L'Isola de' Fiori, alla quale furono guidati da molti uccelli che vedevano andare a quella volta, perchè, essendo tali uccelli terrestri e non marini, fu da lor guidicato che non potevano andare a riposarsi non ad alcuna terra: e poi camminarono tanto per Nordeste che 
presero il capo di Chiara in Irlanda per Loeste: nel qual paraggio trovarono grandissimi venti Ponenti, e il mar non turbarsi. Il che stimavano potere avvenire per alcuna terra che il coprisse di verso Occidente. $\mathrm{Ma}$, perciocchè era già entrato il mese d'Agosto, non volsero tornarsi aa'Isola per paura del verno. Ciò fu più di quaranta anni avanti che si scoprissero le nostre Indie. Ciò gli era confermato dalla relazione fattagli da un marinaro guercio nel porto di Santa Maria, il quale dissegli, che in un suo viaggio fatto in Irlanda vide detta terra, che allora pensava essere parte di Tartaria, che volgeva per L'Occidente, la qual doveva essere quella ch'or chiamiamo Terra di Bacalaos: e che per i cattivi temporali accostar non vi si poterono. Con la qual cosa dice che si conformava un Pietro di Velasco Galego, il quale gli affermò nella città di Murcia in Castiglia che, facendo egli quel cammino d'Irlanda, s'avvicinarono tanto al Noroeste, che videro terra di verso L'Occidente d'Irlandia: la qual egli crede esser quella che un Fermaldomos (Fernão D'Ulmo) tentò di scoprir nel modo che qui narrerò fedelmente, sì come ho trovato negli scritti del padre mio; acciò che si sappia como da picciol cosa vengono alcuni a far fondamento d'un altra maggiore" (6).

A testemunha dos Pleitos de Colón (probanza de Juan Martin, feita em Palos em novembro de 1532) de nome Alonso Vélez Allid, disse

"que lo que sabe es que Martin Alonso Pinzón, llevó aviso de Pedro Vasquez de la Fonteira, que habia ido á descubrir esta tierra con un infante de Portugal decia que por cierto la habian errado y se habian engañado por las yerbas que habian hallado en el golfo de la mar y dijo al dicho Martin Alonso que cuando llegasen á las dichas yerbas y el almirante quisiera volverse de alli que no lo consintiese salvo que siguisen la via derecha, porque era imposible el no dar la tierra y necessidad lo que habian de hacer porque el dicho infante de Portugal por no hacerlo erró la dicha tierra y no llegó alla" (7).

A outra testemunha (Probanza del Almirante) depondo em Madrí em agôsto de 1535, de nome Fernando Valiente, declarou que:

"lo que sabe es que D. Cristobal Colón antes que fuese á negociar con los Reyes Catolicos sobre el descubri-

(6). - Le Histoire della vita e dei fatti di Cristoforo Colombo, pelo seu filho D. Fernando, comentada por Rínaldo Caddeo, Milão, 1930, volume 1, páginas 72 a 76 .

(7). - Cesario Fernandez Duro, Colón e Pinzon, Madrí, 1883, páginas 234 a 235. 
miento, vino á la vila de Palos para buscar favor e ayuda para ir al dicho descubrimiento e posó en el monastero de la Rabida y de alli venia algunas veces á villa de Palos e hablaba con un Pero Vazquez de la Fronteira, que era hombre muy sabio en el arte de la mar e habia ido una vez á hacer el dicho descubrimiento con el infante de Portugal, e este Pero Vasquez de la Fronteira daba aviso al dicho Colón e á Martin Alonso Pinzón e animaba la gente e les decia publicamente que todos fuesen á aquel viaje, que habian de hallar tierra muy rica, e esto que lo sabe este testigo porque vió á dicho Colón e oyó decir lo que tiene dicho al dicho Pero Vasquez de la Fronteira" (8).

Vejamos antes de tudo a parte puramente histórica dessa suposta viagem de Diogo de Teive e mais o seu pilôto ao banco da Terra Nova, para depois estudarmos com o auxílio do almirante Morison (9), reconhecida autoridade em navegação à vela, a parte náutica, justamente a mais importante e que melhor elucida a questão em tela.

Como sabemos, o famoso processo conhecido por Pleitos de Colón, em que o govêrno espanhol procurou anular os privilégios hereditários dos descendentes de Colombo, e os Pinzóns tudo deligenciaram para diminuir a glória do grande Genovês em proveito de Martin Alonso, testemunhas facciosas foram arroladas e interrogatórios ardilosos foram feitos. Portanto, quando temos necessidade de recorrer aos depoimentos de tais testemunhas, devemos usar de grande cautela, se é que desejamos não cometer graves erros, ou pelo menos ser coerentes. Foi certamente assim raciocinando que o notável americanista Henry Vignaud, apesar de em 1911 conhecer os documentos de que em 1933 se serviu Jaime Cortesão para tentar identificar o pilôto Pedro de Velasco dos textos de Fernando Colombo e de Bartolomeu Las Casas, com Pedro Vasquez de la Fronteira dos depoimentos aqui transcritos das testemunhas dos Pleitos de Colón, não se abalançou a tanto, apenas se limitando a fazer uma mera insinuação (10).

Jaime Cortesão diz que Pedro de Velasco seria a tradução em espanhol do latim Petrus Velascus ou Velasci, visto que no latim estava escrita por Colombo a nota de onde originou o texto de seu filho D. Fernando e estas grafias eqüivalem a Pedro Vasquez. Contra essa identificação tentada por Cortesão apresenta o professor Duarte Leite duas objeções a saber:

(8). - Duro obra citada, páginas 253 a 254.

(9). - Obra citada, páginas 21 a 29.

(10). - Henry Vignaud, Histolre Critique de 12 Grande Entreprise de Cristophe Colomb, Paris, 1911, volume II, páginas 22 e 23 e nota 27. 
não só é contestável que a nota originária estivesse escrita em latim, pois não valem os argumentos aduzidos em favor desta suposição, mas também um dos pilotos era natural de Palos de Muguer e o outro de Fronteira, diferença importante mas esquecida.

A nossa contestação à identificação feita por Cortesão é a seguinte: Pedro de Velasco, segundo os dois historiadores referidos (D. Fernando e Las Casas), após ter em companhia de Diogo de Teive descoberto a ilha das Flores, navegou tanto rumo nordeste até que o Cabo Claro da Irlanda ficou-lhe a este e avistou terra ao poente. Portanto o nome de Pedro de Velasco está ligado a uma viagem ao ocidente, porém nas altas latitudes, acima de $\mathbf{4 0}$ graus. Quanto a Pedro Vasquez de la Fronteira, as fantasiadas viagens que disse ter realizadas ao Ocidente, inclusive uma com indeterminado infante de Portugal, foram nas baixas latitudes, no mar percorrido por Colombo na ida da sua primeira viagem ao Novo Mundo onde existiam "las yerbas", isto é, no denominado Mar de Sargaços. E, depois, não é admissível que, se Pedro Vasquez de la Fronteira, fôsse o pilôto Pedro de Velasco, companheiro de Diogo de Teive, não fizesse alarde (como era costume na época e como atestam os documentos) de ter também navegado nas altas latitudes, quando pùblicamente se gabava de ter atingido o Mar de Sargaços.

Declarou a testemunha dos Pleitos lde Colón de nome Fernando Valiente, como já vimos, que Pedro Vasquez de la Fronteira "daba aviso al dicho Colón e á Martin Alonso Pinzón, e animaba la gente e les decia publicamente que todos fuesen á aquel viaje, que habiam de hallar tierra muy rica". No entanto, da relação dos nomes de todos os tripulantes dos navios que partiram de Palos em busca dessa "tierra muy rica", não consta o nome de Pedro Vasquez de la Fronteira. Por que? Será que não tinha "gana" de ficar rico, preferindo não acompanhar Colombo na sua aventura, para ser assassinado, antes da volta triunfal do Almirante?

Não se precisa ser muito atilado para se perceber que êste suposto pilôto não passava de um dos astuciosos agentes encarregados por Colombo e Martin Pinzón, de aliciar tripulantes para a temerária viagem rumo ao Ocidente desconhecido. Tôda propaganda que fazia da "tierra muy rica", tôda a sua gabolice de ter tentado encontrá-la com um infante de Portugal, era justificada, porque as dificuldades para alistar gente 
para tal emprêsa eram tão grandes, que Fernando e Isabel tiveram necessidade de baixar um édito em 30 de abril de 1492, garantindo a todos que se alistassem nas naus de Colombo nada terem a temer com relação a qualquer crime praticado até aquela data, tendo êsse édito validade durante tôda a viagem e mais dois meses após o retôrno da expedição (12).

Anulada assim a identificação tentada por Cortesão, de Pedro de Velasco com Pedro Vasquez de la Fronteira, restanos analisar o que sôbre a viagem de Diogo de Teive e mais o seu pilôto, escreveu Fernando Colombo.

Segundo êste historiador, Pedro de Velasco afirmou a Colombo no convento de la Rabida, que após ter descoberto a ilha das Flores (com Diogo de Teive), navegou tanto rumo nordeste até que o Cabo Claro da Irlanda lhe ficou a leste e percebeu sinal de terra ao Ocidente, mas não foi à procura dela por ser o mês de agôsto e temer o inverno. Depois, em Múrcia, Pedro de Velasco disse a Colombo que quando navegava naquela viagem, da Irlanda, rumou tanto a nordeste, até que avistou terra ao poente.

Ora, o simples fato de ter Pedro de Velasco declarado a Colombo que avistou terra ao Ocidente da Irlanda, sem que tivesse a ela aportado, não pode em absoluto constituir prova a favor da descoberta do banco da Terra Nova ou de outra qualquer região da América setentrional, em agôsto de 1452, por Diogo de Teive e seu pilôto. A história dos descobrimentos marítimos está cheia de notícias de terras e ilhas avistadas pelos navegantes dessa época e que até hoje não foram encontradas.

Diz Morison:

"Houve mais de um falso - "Terra à vista"! - na primeira viagem de Colombo à América. A ilusão de avistar terra é um dos mais comuns fenômenos marítimos. Uma nuvem no horizonte ou uma linha de nevoeiro podem ser tomadas fàcilmente por terra, sobretudo quando se está ancioso por avistá-la. Tal fato é conhecido de todos os que fazem viagens marítimas e navegam em alto mar. Bartolomeu Las Casas diz no capítulo XIII da Historia de las Indias, ter extraído das notas que the forneceu Colombo, várias notícias de terras avistadas não longe dos Açores. A ilha Brasil assinalada nos mapas na altura da Irlanda, era uma dessas ilhas constantemente avista-

(12). - Navarrete, Martin Fernandez de, Coleccion de los viajes y descubrimientos que hicieron los espafioles desde fin del siglo XV. Editorial Guarania, Buenos Aires, 1946, tomo II, páginas 25 e 26. 
das. Segundo o embaixador espanhol na Inglaterra, os habitantes de Bristol eqüiparam navios, a partir de 1491 até 1497, para irem à procura das ilhas Brasil e das Sete Cidades. Existem relatos pormenorizados da descoberta da imaginária ilha Brasil nos séculos XVII e XVIII, e o Almirantado não retirou de sua carta geográfica o Rochedo Brasil a não ser depois de 1875 . O próprio professor Westropp pensa tê-la avistado da costa irlandesa em 1872 , e os pescadores da ilha Aran ainda acreditam que a ilha Brasil aparece cada sete anos. Os açoreanos, muito antes do descobrimento da América por Colombo; até 1770, viviam a avistar novas ilhas além do seu arquipélago. Em 1593 o govêrno português ainda concedia carta de doação ao capitão donatário da ilha de São Miguel, garantindo-lhe a posse de uma ilha que de tempos em tempos aparecia perto da que habitava" (13).

Encaremos agora a questão sob o ponto de vista náutico, com o valioso auxílio do professor Morison.

Cortesão é de parecer que Fernando Colombo adulterou e e mutilou as próprias fontes que utilizou ao escrever a história da vida de seu pai, isso com o objetivo premeditado de diminuir de importância os indícios que seu pai tinha colhido dos navegantes portuguêses sôbre a existência de terras ao Ocidente. O extravio de tôda a documentação pertencente a Colombo e referente à viagem em apreço, bem assim dos originais da História de Cristobal Colón, escrita pelo seu filho D. Fernando, não constituem obstáculos para Cortesão sustentar essa temerária opinião. Com o escopo de retificar essas adulterações e mutilações que diz ter praticado Fernando Colombo, por sua vez Cortesão altera e adultera radicalmente os textos da história de Colombo escrita pelo seu referido filho e Las Casas, na parte referente ao rumo que Diogo de Teive e mais o seu pilôto Pedro de Velasco tomaram após terem descoberto a ilha das Flores, procedimento êste que não é bonito para um historiador do seu quilate. Nos textos aludidos, Teive e seu pilôto partiram em procura da imaginária ilha Antilha ou Sete Cidades e após terem navegado 150 léguas além do Faial, sem nada encontrarem, na volta descobriram a ilha das Flores e desta ilha tomaram o rumo nordeste e navegaram tanto, que o Cabo Claro da Irlanda ficou a leste dêles. Cortesão alterou para noroeste o rumo da navegação de Teive e mais o seu pilôto, a partir do ponto em que êles atingiram a ilha das Flores, pois não concorda que êsses navegantes tenham tomado a direção

(13). - Morison obra citada, páginas 27 a 29. 
(nordeste) da Irlanda, mas sim aquela (noroeste) do banco da Terra Nova.

Acontece, porém, que essa adulteração tão radical, feita por Cortesão nos textos de Fernando Colombo e Bartolomeu Las Casas, em absoluto não redunda em favor da sua tese porque, de acôrdo com a Pilot Chart of North Atlantic, publicada mensalmente pelo United States Hydrographic Office, os ventos predominantes em agôsto são os de oeste e noroeste entre 45 a 60 graus de latitude norte e de costa a costa. Portanto não seria possível a um navio de vela, partindo de qualquer ilha dos Açores, realizar uma viagem rumo noroeste, em direção à Terra Nova ou a qualquer outra região da América Setentrional, como supõe Cortesão ter realizado Teive (14). Ao contrário, uma viagem rumo nordeste, como está nos textos citados, em direção à Irlanda, partindo de qualquer ponto dos Açores, é favorecida justamente por êsses ventos que sopram de oeste e noroeste, durante cêrca de 8 meses em cada ano. Tudo indica que Teive e mais o seu pilôto, após terem descoberto a ilha das Flores, navegaram, como está nos textos referidos, rumo nordeste até que atingiram a Irlanda, e não como pretende Cortesão em direção a noroeste, em procura da Terra Nova. Acresce ainda esta circunstância posta em relêvo por Morison: em vista dos predominantes ventos de oeste nos Açores e zona vizinha, é muito difícil que um navio de vela partindo dêste arquipélago (ilha das Flores), com destino à Irlanda (como dizem os textos terem feito Teive e seu pilôto), fôsse de tal modo afastado de sua rota ao ponto de avistar o banco da Terra Nova (15) .

George E. Nunn, tratando da primeira viagem de Colombo ao Novo Mundo, estuda minuciosamente o regime dos ventos e correntes marítimas no Atlântico Norte, tanto na zona onde estão compreendidas as ilhas dos Açores como naquela onde se acham as Canárias, concluindo por demonstrar a impossibilidade de qualquer navio de vela, partindo de qualquer ilha dos Açores, navegar por longo tempo em direção la oeste ou noroeste, devido aos fortes ventos predominantes de oeste (16).

Não podendo contestar essa verdade meteorológica a que se referem Morison e Nunn, procura Damião Peres ladear a questão dizendo:

(14). - Morison, obra citada, página 24 .

(15). - Morison, obra citada, página 27.

(16). - George E. Nunn, The Geographical Conceptions of Columbus, New York, 1924, páginas 31 a 53 . 


\begin{abstract}
"Ao atingir a Irlanda, podia Diogo de Teive prosseguir na direção da Islândia em procura de melhores condições de regresso. Procedendo assim, encontraria aí ventos de leste, entre essa ilha e a Groelândia, que o levariam, como outrora sucedera com os normandos, às vizinhanças da América mais setentrional, podendo então navegar para o sul e sueste, completando assim o seu regreso" (17).
\end{abstract}

Acaso Damião Peres quer nos convencer de que os nautas portuguêses da época henriquina estavam a par do modo como os normandos atingiram a Groenlândia e regiōes circunvizinhas? Ou quem sabe, já naquela época existiam cartas náuticas assinalando com precisão os ventos que imperam no Atlântico Setentrional?

Mais de uma vez fizemos alusão ao fato de terem Diogo de Teive e mais o seu pilôto partido após a descoberta da ilha das Flores, em direção a nordeste avistando a Irlanda. Com que intuito teriam êsses navegantes tomado tal direção e não a da Terra Nova, como pretende Cortesão? Quer nos parecer que assim procediam visando o encôntro da mítica ilha Brasil assinalada nos mapas da época, justamente a oeste da parte sul da Irlanda, à semelhança do que se observa no mapa de Bartolomeu Pareto reproduzido no Atlas de Kretschmer e em outros.

Finalizando, diz Cortesão que o conjunto de circunstâncias geográficas, tais como a existência de mui fortes ventos de oeste estando o mar tranqüilo, indício da existência de terra próxima, e o sinal de próximo inverno em pleno agôsto - só no banco da Terra Nova se pode dar. E acrescenta: estas coincidências dos textos de Las Casas e de D. Fernando, com as realidades geográficas tão singulares e localizadas, é uma prova mais que valiosa do que aquela fornecida pelos documentos (18).

A êsses argumentos de Cortesão, responde Morison com a sua conhecida autoridade, do seguinte modo: forte vento de oeste, mar tranqüilo e uma alteração no ar a prenunciar inverno, podem ocorrem em qualquer ponto entre a América e a Europa e entre 45 a 60 graus de latitude norte e são frequientemente observados hoje em dia pelos navegadores dessa extensa zona. E, quanto à tranqüilidade do mar, nas proximidades do banco, declara Morison que tal fenômeno não acontece em absoluto, conforme constatou durante 7 viagens que no verão, realizou a essa paragem (19) .

(17). - o século dos Descobrimentos, Suplemento Literário do jornal o Estado de S. Paulo, 12 de novembro de 1960 , página 1 .

(18). - Arquivo Histórico da Marinha, Lisboa, 1933, volume I.

(19) : - Morison, obra citada. páginas 23 e 24. 
Duarte Leite com aquela visão penetrante quando estuda e interpreta documentos, levantou uma dúvida difícil de ser afastada, a qual abala nos seus alicerces a tese de Jaime Cortesão, tal aquela de ter em 1452 Diogo de Teive e seu pilôto Pedro de Velasco, realizada a viagem na qual teriam avistado o banco da Terra Nova.

\section{Diz Duarte Leite o seguinte:}

"Só à vista da descrição de Las Casas se fixou em 1452 o ano da descoberta da ilha das Flores, que deveria ser acompanhada pela da ilha quase contígua do Corvo. E' de desconfiar a data marcada a êste acontecimento cêrca de 40 anos anterior à sua narração por Colombo: e em verdade ela é abertamente contraditada por um testemunho oficial português. Um diploma de 28 de janeiro de 1474 confirma a aquisição por Fernão Teles das "ylhas que chamam as Foreyras, que pouco ha que acharom Diogo Teyve, seu filho" ao qual "ficarom por morte do dito seu pay" que "as ditas ylhas achou e tinha". Geralmente se crê - e também J. Cortesão - que "Foreyras" é engano por "Floreyras", designação comum àquela que conserva e à vizinha do Corvo: ora por mais elasticidade que queiram dar às palavras "há pouco", não é admissível distendê-las até 22 anos, que tantos seriam necessários se a ilha ou as ilhas das Flores tivessem sido descobertas em 1452".

"Objetar-se-á que outro diploma anterior, de 20 de janeiro de 1453 , dôa ao duque de Bragança a "ilha por nome chamada do Corvo", o que exige descoberta antes da data, não se diz por quem. Mas isto põe-nos em presença dum enigma de difícil decifração, pois se tal ilha é a atual do nome, não se percebe como o diploma de 1474 diga que Diogo de Teive a "achou e tinha", e por morte a deixou ao seu filho, e se difere, não se atina com qual ela seja, visto pertencerem a D. Henrique as sete dos Açores: para mais a das Flores por vêzes se chamou do Corvo, o que melhor se coaduna com a doação a tão alta personagem, já que a atual do Corvo é pequeníssima. Sem discutir as várias hipóteses que ocorrem para explicar a contradição entre dois diplomas, contento-me com duvidar do ano de 1452 em que J. Cortesão diz feita a viagem de Diogo de Teive".

" $E$ seria êste descobridor escudeiro de D. Henrique, qualidade que nem o diploma de 1474 , nem o texto de Fernando Colombo, nem qualquer outro documento de meu conhecimento lhe confere? Há notícia dum Diogo de Teive, que tinha, e a quem o Infante concedeu, em dezembro de 1452, a montagem na Madeira dum engenho hidráulico de moer cana sacarina: mas não deve ser o descobridor, 
porque em agôsto dêsse ano ainda navegava de retôrno ao Faial, e não é crível que antes de dezembro estivesse convertido de navegante em fabricante de açúcar na Madeira. Como não devia haver dois escudeiros henriquinos do mesmo nome, é provável que não o fôsse o descobridor, o que transtorna os resultados da análise de J. Cortesão" (20).

À vista do exposto, a suposta descoberta do banco da Terra Nova em agôsto de 1452 por Diogo de Teive e seu pilôto Pedro de Velasco, com muita boa vontade poderá ser incluída na relação das fracassadas tentativas dos ilhéus portuguêses, notadamente dos açoreanos, em procurar as imaginárias ilhas Brasil, Antilhas ou Sete Cidades.

T. O. MARCONDES DE SOUZA

Da Sociedade de Estudos Históricos de São Paulo Da Société des Américanistes de Paris.

(20). - Duarte Leite, obra citada, páginas 79 a 81 . 